\title{
Engajamento Ambiental Como Artifício de Branding de Moda
}

\section{Marcus Teixeira Cardoso}

Mestrando em Branding pela Faculdade de Comunicação da Universidade de Brasília, Graduação em Comunicação Social com habilitação em Jornalismo pela FACHA - Faculdades Integradas Hélio Alonso/ markcardoso@gmail.com

Orcid: 0000-0002-6204-0353 / http://lattes.cnpq.br/4218769098375333

\section{Edmundo Brandão Dantas}

Doutor em Ciência da Informação pela Universidade de Brasília, Mestre em Engenharia de Produção pela Universidade Federal de Santa Catarina e Graduado em Ciências Econômicas pela Associação de Ensino Unificado do Distrito Federal. edmundod@terra.com.br

Orcid: 0000-0002-6204-0353 / http://lattes.cnpq.br/5970190862997671

Enviado 28/06/2018 / Aceito 28/11/2018 


\title{
Engajamento Ambiental Como Artifício de Branding de Moda
}

\begin{abstract}
RESUMO
O presente artigo trata de observar a estratégia de marca da grife carioca Osklen com o lançamento da coleção ASAP - As Sustainable As Possible (em uma tradução livre: o mais sustentável possível), para a estação de inverno do ano de 2018. Para isso, foi desenvolvida análise qualitativa de comunicação, ambientação de loja, escolhas e decisões de estilo para a composição da coleção, bem como o discurso construído em função desse lançamento: seja na voz do diretor criativo, seja por meio de peças e anúncios da campanha publicitária desta coleção. De acordo com o estudo bibliográfico desenvolvido, com método exploratório, é possível identificar a construção desse discurso - o da responsabilidade ambiental - como artifício de branding ante ao consumidor, com apoio bibliográfico de teóricos da área como Mary Douglas, Baron Isherwood, Marshal Sahlins e Kevin Roberts.
\end{abstract}

Palavras-chave: Moda; Branding; Responsabilidade Ambiental. 


\title{
Ambiental Engagement as a Fashion Branding Tool
}

\begin{abstract}
The present paper is a result of the observation work over Osklen's brand strategy for the launch campaign of its collaction 'ASAP - As Sustainable As Possible' during the winter season of 2018. For this purpose, a qualitative analysis of brand communication was developed, as well as interior layout of stores, choices and decision of the style team on composing this collection and the brand speech which was stablished because of this launch: starting on the brand's creative diretor voice and going trough communication pieces and advertising campaign.

After all the bibliographic study, via exploratory method, it was possible to identify the construction of this discourse based on "ambiental responsibility" cause as a branding tool.
\end{abstract}

Keywords: Fashion; Branding; Ambiental Responsibility. 


\section{ENGAJAMENTO AMBIENTAL COMO ARTIFÍCIO DE BRANDING DE MODA}

"O mais sustentável possível. O quanto antes". Em um trocadilho com a expressão inglesa as soon as possible muito conhecida no meio corporativo pela sigla ASAP -, a marca de moda de origem carioca Osklen apresentou sua mais nova coleção para a estação de inverno de 2018. Com esse discurso, o que se propõe na moda - cujo ritmo obedece à toada da efemeridade dessa indústria, pontuada por Gilles Lipovetsky (1989) - é uma produção e um consumo de moda conscientemente sustentáveis: por produção de moda, podemos considerar a identidade da marca; por consumo de moda, o comportamento do seu público. Tudo porque a urgência parece dar a tônica contemporânea tanto dos desejos dos sujeitos quanto do ritmo da indústria criativa, que, em alguns casos, lança até cinco coleções por ano. "A moda não tem conteúdo próprio; ela não está ligada a um objeto determinado, mas é, em primeiro lugar, um dispositivo social caracterizado por uma temporalidade particularmente breve" (LIPOVETSKY, 1989, p. 25).

É nessa seara, em que o novo precisa ser novo de novo cada vez mais, num espaço de tempo cada vez menor, que as marcas de moda lançam mão de manobras e artifícios de branding em busca de diferenciação entre si e da tão almejada lealdade dos indivíduos consumidores. Nela, o desafio está na construção de uma marca (branding) que se destaque no cenário em que se insere, com reais razões para que o indivíduo acredite e deseje comprar aquele discurso, uma vez que ele é a roupagem capaz de vestir meros commodities - peças de roupa, calçados e acessórios - com identidades possíveis e desejáveis, além de valores intangíveis, como responsabilidade social, consciência 
ambiental, consumo consciente, sofisticação, elegância, popularidade, entre outros.

E como argumenta Appadurai (2008, p. 15), em Simmel, "o valor jamais é uma propriedade inerente aos objetos, mas um julgamento que sujeitos fazem sobre eles". Citado por Appadurai, Simmel (1978) destaca que os objetos se tornam valiosos por opor resistência ao nosso desejo de possuí-los. Por uma das vias possíveis de gerar desejo e agregar valor na percepção dos indivíduos - a responsabilidade ambiental -, chega-se a uma reflexão acerca da sustentabilidade nas marcas de moda, tema que este trabalho busca investigar a partir da análise da comunicação e do posicionamento da marca carioca Osklen para a sua coleção ASAP.

\section{O AMOR COMO ESTRATÉGIA DE MARCA}

Roberts (2004), em Lovermarks - o futuro além das marcas, defende que os seres humanos precisam de amor, seja amando o outro, a si próprio, a família, o trabalho, os objetos. De acordo com esse autor, tal amor precisa ser correspondido para que sobreviva.

O processo de humanização das marcas, nas últimas duas décadas, estrategicamente, visa ao relacionamento possível com esses seres humanos. É por meio de suas marcas que as empresas podem estabelecer essa relação fantasiosamente interpessoal com seu público, posicionandose como uma persona. Assim, as marcas podem ser percebidas como energéticas, atléticas, elegantes, sofisticadas, austeras, populares, inovadoras, clássicas, entre outras características humanizantes.

Se humanizadas as marcas passam a sentir e agir como as pessoas. É como as pessoas que as marcas também passam a adotar causas "pessoais", depositando nelas amor e engajamento, o que Ihes permite mobilizar os indivíduos e 
sedimentar seu relacionamento com eles. A intenção, nesse ponto, é atender exigências mercadológicas de diferenciação de marca de modo a atingir e cativar os indivíduos que integrarão o público da marca. Tais causas da agenda contemporânea vão desde as sociais e de gênero atualmente, populares entre as marcas de moda - até as ambientais. Desse modo, as marcas traçam seus posicionamentos, os quais as diferenciam entre si e fidelizam clientes não só pela qualidade de seus produtos e questões de custo-benefício, mas por meio dos discursos que constroem e das causas que apoiam.

Segundo Keller e Lehmann (2006), o termo branding surgiu em meados dos anos 2000 graças à crescente percepção de que as marcas são um dos bens, ainda que intangíveis, mais valiosos que as companhias possuem. No lugar dos produtos e das empresas, é o portfólio de marcas o real patrimônio de companhias como Unilever, InBrands, Kraft, entre outras gigantes do mercado global.

Dentre as "causas pessoais" possíveis para marcas humanizadas, destaca-se a ambiental. Quanto ao meio ambiente, responsabilidade ambiental empresarial é um conjunto de atitudes voltado para o desenvolvimento sustentável do planeta. Essas atitudes não têm sua produção econômica como único norte estratégico, mas uma intervenção no tecido social que leva em conta o crescimento econômico ajustado à proteção do meio ambiente na atualidade, para as gerações futuras, garantindo a sustentabilidade de suas ações como ferramenta de gestão (MUNDIM, 2012).

Após personificarem-se e humanizarem-se, as marcas se submetem a um suposto "processo civilizatório", a partir do qual se apresentam como cidadãs. E, como tais, partem do princípio de que, com o Estado cada vez menor no Ocidente, podem atuar nessa brecha, exercendo um papel social, 
político e/ou ambiental, o que redesenha o campo no qual atuam o público e o privado por meio dessa projeção positiva de suas marcas:

Quando decidem implantar ou assumir programas de responsabilidade social, as empresas justificam sua atitude sob o escudo da cidadania, da preocupação com a sociedade, da solução de problemas sociais para os quais o Estado aparentemente estaria se mostrando incompetente. Além de não admitirem que se trata de uma intervenção social de natureza política, as empresas também fogem do estigma das razões mercadológicas, seja porque há uma conotação fortemente negativa em associar a responsabilidade social com sua estratégia de mercado, já que muitos críticos a este movimento o enxergam apenas como retórica de promoção empresarial; seja porque também é mais interessante em termos de imagem institucional trabalhar a ideia de que o mundo corporativo assume nova postura, para além do lucro e do seu interesse direto. Não há como negar, porém, que associar a empresa a uma causa social é uma estratégia de construção de reputação institucional muito poderosa. É um instrumento que gera mídia espontânea, pelo fato de posicionar a organização sob uma nova perspectiva na mente dos consumidores, projetando a imagem de uma instituição engajada, atuante, inserida na comunidade em que atua (MARTINELLI; SANTA CRUZ, 2007, p. 3).

Seguindo essa tendência estratégica, a marca Osklen que surgiu como marca de casacos esportivos para neve na virada da década de 1980 para 1990 e se estabeleceu como o "Reino Unido de Ipanema", uma das principais marcas de luxo brasileiro já espalhada pelo mundo - se apropriou do discurso ambientalmente responsável ainda nos anos 1990, quando lançou sua primeira camiseta feita com cânhamo, fibra resistente que não utiliza produtos químicos em sua produção. Também foi naquele ano que a marca iniciou o desenvolvimento do algodão orgânico em parceria com a Embrapa e a ONG Esplar, no Ceará ${ }^{1}$.

\footnotetext{
${ }^{1}$ As informações foram retiradas da apresentação do instituto, em seu próprio site. Disponível em: http://institutoe.org.br/sobre/
} 
Tal inovação foi o embrião do que viria a ser o projeto eFabric em parceria com o Instituto-E, em 2006, o qual é também uma iniciativa de Oskar Metsavaht, fundador e diretor criativo da Osklen. Como apresentado em seu site, o instituto desenvolve projetos socioambientais e tem por missão "transformar e posicionar o Brasil como 'o país do desenvolvimento humano sustentável', por meio da criação e gestão de uma rede que potencialize sinergias entre diferentes iniciativas e agentes da sociedade" (2018). "A Osklen, junto com o Instituto-E, fez um trabalho notável: dedicou seu tempo, talento e dinheiro para pegar os produtos, melhorar as qualidades, ensinar o apuro estético e testar esses materiais à venda", pontua Oskar, em entrevista a Pedro Duarte, para a revista Cause. Tais iniciativas são importantes para dar corpo ao discurso de marca. No branding, um discurso vazio não convence os indivíduos e não permanece de pé por muito tempo. "Você só pode pensar nisso se tiver algo por trás para tangibilizar. É preciso ter conceito e, para ter conceito, tem que haver experiência legítima, daí então você está criando moda e não fazendo roupa".

\section{BRASILIDADE E AMOR À NATUREZA EN VOGUE}

Com o lançamento da nova coleção ASAP, ao visitar uma loja da marca, o que se observa é uma disposição de publicidade um pouco mais suave, como quem pretende consumir menos papel. As típicas fotos ampliadas parecem menos presentes. E o pouco de programação visual que se vê são adesivos de vitrine que chamam a atenção para os grandes números das benfeitorias ambientais da marca com essa coleção, dando destaque aos resultados de sua ecoeconomia² a partir da adoção do PET reciclado na trama

2 Ecoeconomia é uma nova proposta econômica, cunhada pelo analista ambiental estadunidense Lester Brown em 1980, na qual se consideram a ecologia e seus sistemas de suporte e reposição. Ao 
dos tecidos que foram utilizados nessa mais recente produção.

Nas araras da loja, a cartela de cores é totalmente em escala de cinza, com raríssimos pontos de cor em rosé e verde militar (vide Figura 1). Os tecidos têm aspecto cru, livres das lavagens tão típicas das produções contemporâneas da moda. A intenção é, com essa coleção, utilizar o mínimo de recursos hídricos, visto que tinturaria e lavanderia são os principais vilões, na indústria têxtil, do meio ambiente.

Figura 1: Vitrine da loja Osklen no Brasília Shopping.

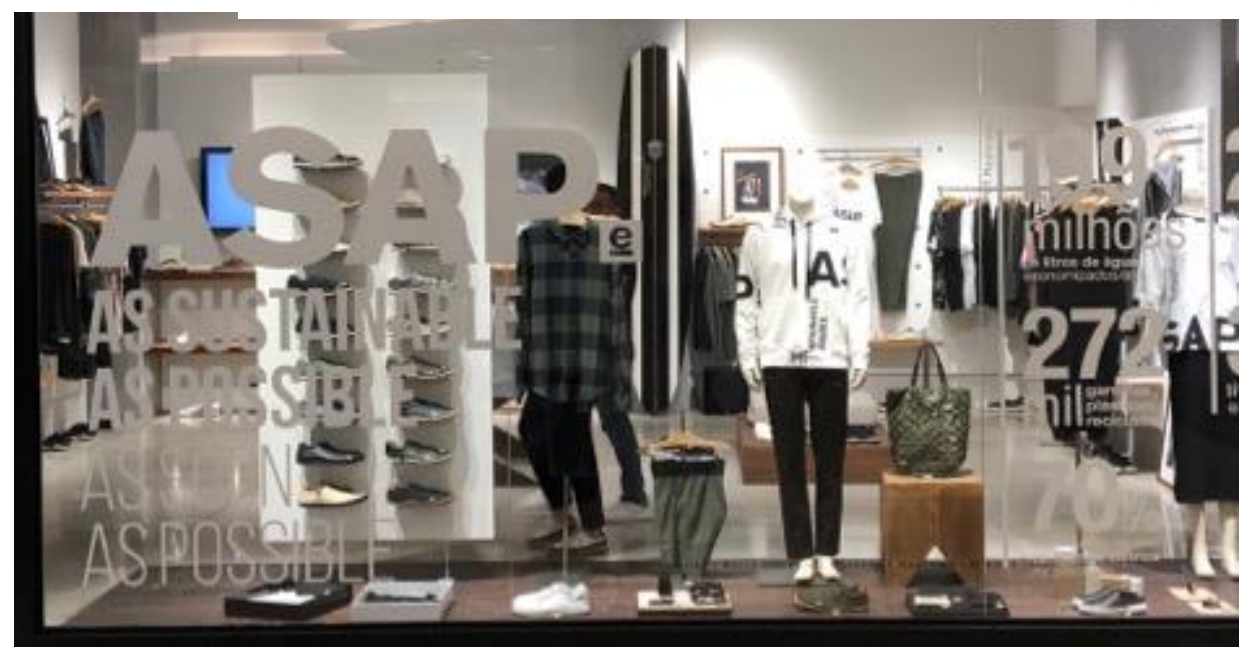

Fonte: acervo pessoal.

Em uma atitude de branding, o conceito da coleção ASAP e o atual posicionamento da marca também se fazem notar no discurso dos funcionários. Ao final de uma experiência de compra dessa coleção da Osklen, o consumidor é convidado pelo vendedor, que finaliza os processos financeiros, a levar apenas uma sacola, já que ele comprou uma peça para presente e uma para si. "Posso colocar a sua camiseta na mesma sacola do presente?", sugeriu o vendedor na loja da marca, no Brasília Shopping (Brasília-DF), em 29 de março de 2018.

refutar a economia clássica, que assegura que as matérias-primas são recursos naturais infinitos, enquanto o trabalho, que é finito, tem valor, a ecoeconomia propõe que, nos dias de hoje, essa teoria praticamente teria se invertido (BROWN, 2003). 
Além da experiência de marca em uma de suas lojas, o discurso publicitário permite a percepção, por parte do consumidor, de uma marca socioambientalmente responsável. A exemplo do anúncio de duas páginas veiculado na edição de março de 2018 da revista Elle, intitulada Girl Talk (Figura 2), a Osklen divulga sua ASAP com fotos que não preenchem a área total da página, deixando espaços em branco para o olho respirar. Nas três fotos utilizadas na composição, uma destaca o manifesto ASAP: Ethical, social, sustainable production, o que, em tradução livre, pode ser lido como "produção ética, social e sustentável". No rodapé de uma das páginas, há um parágrafo que enaltece a escolha da marca de produzir 170 peças com seu e-Fabric, tecnologia têxtil cunhada pela Osklen, há uns anos, para designar seus tecidos que utilizam "matérias-primas sustentáveis, muitas vezes produzidas por comunidades, traduzindo o pioneirismo e compromisso da Osklen com a moda ética através do design e estilo autoral, conceito do novo luxo" (OSKLEN, 2018, p. 20). Oskar Metsavaht corrobora essa afirmação do anúncio de sua marca em entrevista à revista Cause quando demonstra um esforço por ressignificar o luxo e diz que tais produtos sustentáveis "são uma jóia. Primeiro porque é praticamente exclusivo. Segundo porque a cadeia por trás é nobre. E terceiro porque nós estamos dizendo que é cool e sofisticado".

Por fim, a marca aproveita o espaço publicitário para destacar que, com essa atitude, mais resíduos estão sendo transformados em moda, o que promove a economia circular, de reuso e reaproveitamento de matérias-primas, numa tentativa de impedir que esse material vá parar no meio ambiente. Em um esforço de validar o discurso de marca, nota-se a presença, tão incomum à redação publicitária, do crédito "Fonte: Coppead-UFRJ", ao final do 
texto. Ao invocar o nome da Coordenação de Pós-Graduação em Engenharia e Administração da Universidade Federal do Rio de Janeiro, a marca de moda tenta se livrar dos estigmas que o discurso publicitário e de marketing já adotou ante a desconfiada opinião pública como forma de endossar sua atitude com o aval de uma instituição famosa por seus relatórios sustentáveis e por seus cursos na área. $A$ instituição também é citada como fonte no merchandising visual da marca e nas comunicações digitais que apresentam números referentes à reciclagem.

Figura 2: Anúncio publicitário.

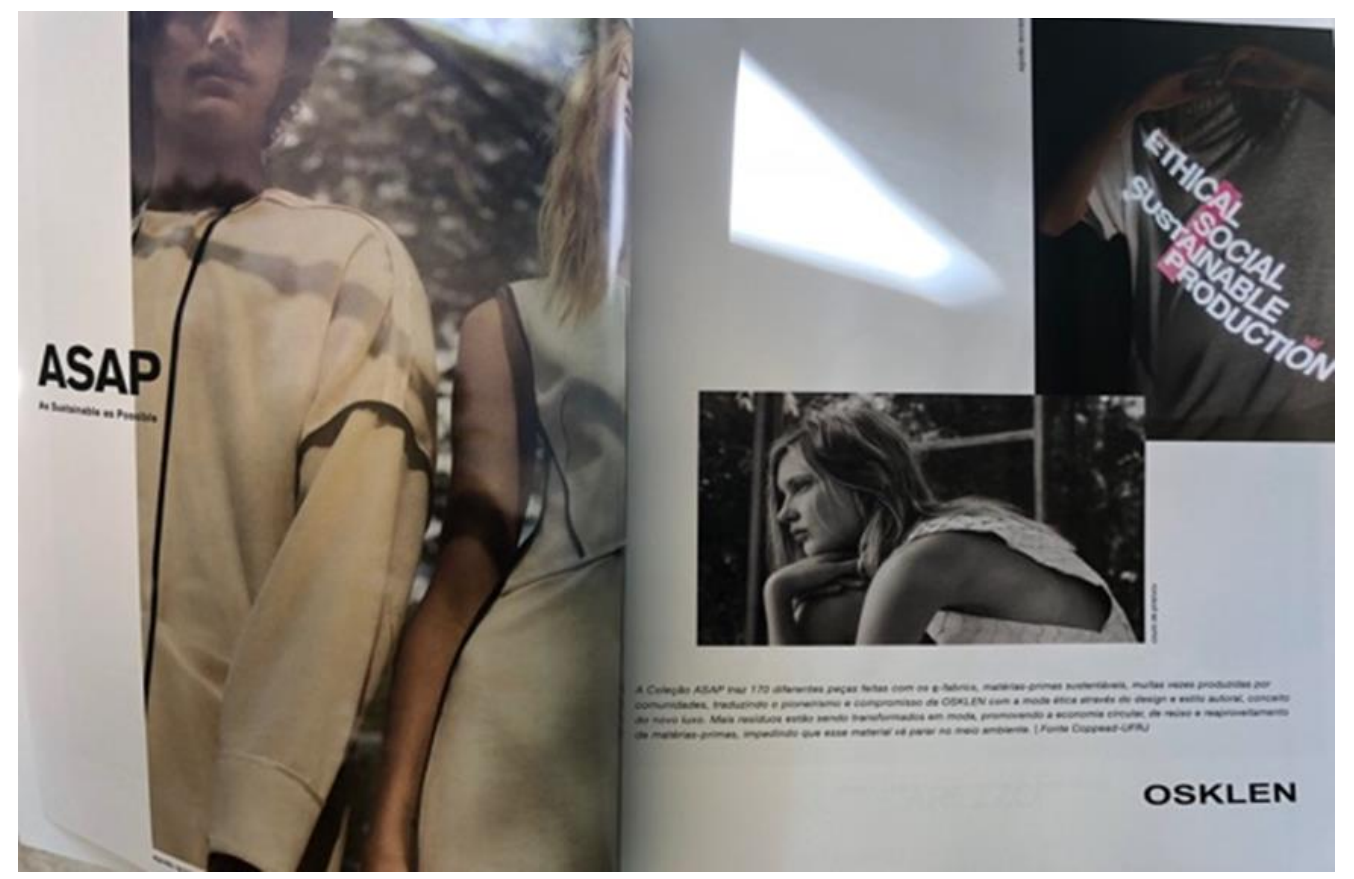

Fonte: Elle Brasil, edição Abril 2018. 
Figura 3: Exemplos do discurso imagético que a marca tenta estabelecer por meio de sua comunicação nas

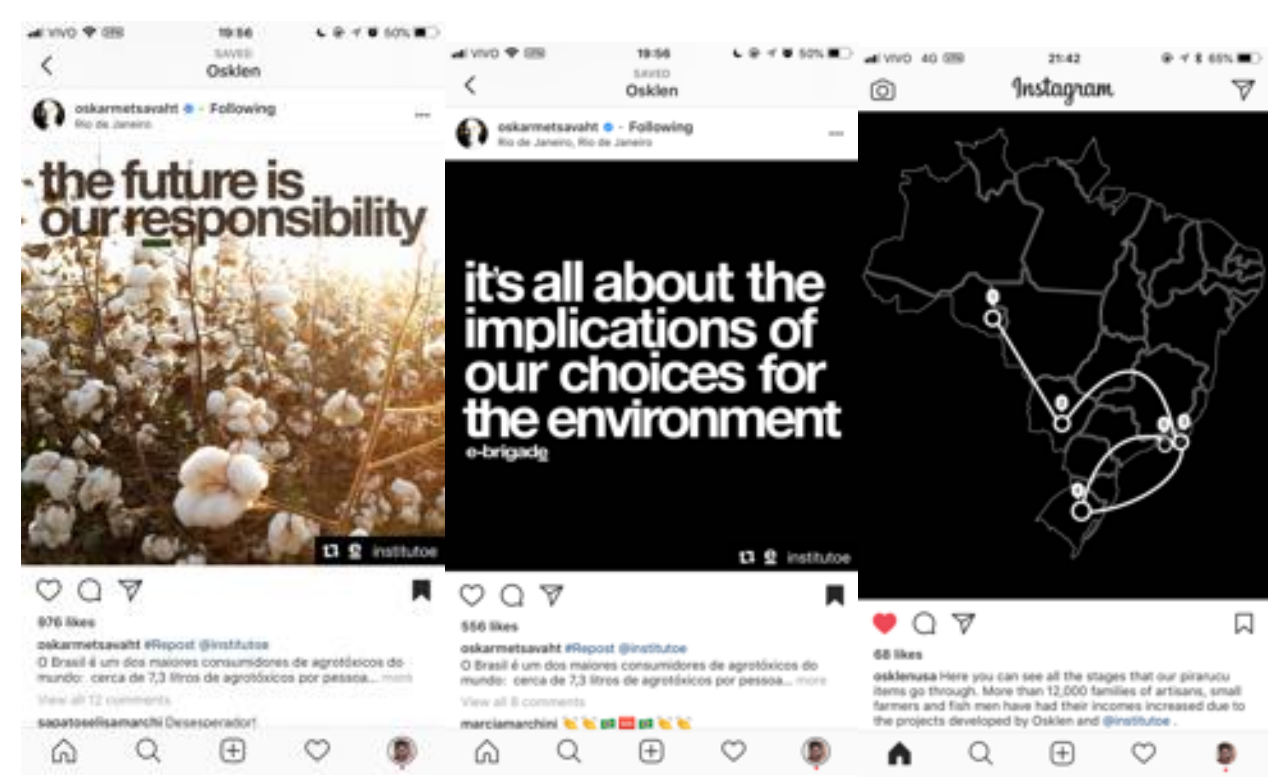

Fonte: Instagram da Osklen, 2018.

Independentemente do discurso, há quase duas décadas, o conceito de sustentabilidade permeia as criações da marca e, mais que isso, confere assinatura visual a elas - como é o caso do couro de pirarucu tão iconicamente Osklen. Mas só agora, quase 20 anos depois, com o Instituto-E já consolidado, é que a marca decidiu lançar uma coleção totalmente desenhada em cima desse conceito. Em matéria jornalística veiculada em abril de 2018, a Vogue Brasil destaca que a grife carioca vem defendendo a sustentabilidade como bandeira muito antes de o assunto entrar na pauta do dia no mercado da moda:

Há 20 anos, Oskar Metsavaht, fundador da Osklen, tem feito jus ao seu sobrenome de origem estoniana. "O significado é guardião das florestas", conta ele, com orgulho. No fim deste mês, quando a Osklen desfilar seu inverno 2018 no São Paulo Fashion Week, o gaúcho vai colher o que vem plantando e pesquisando há duas décadas: cerca de $98 \%$ das peças que cruzarão a passarela são eco-friendly, consagrando a bandeira e a filosofia de vida de Oskar (DISITZER, 2018). 


\section{CONSUMIR PARA SER}

Culturalmente, na pós-modernidade, os indivíduos lançam mão do consumo como forma de construir sua identidade. E para tal, um indivíduo consome pelos motivos mais diversos: para satisfação do desejo, para obter algum tipo de aprovação social, para emitir mensagens, em busca de pertencimento de determinado grupo social... Consomem-se, então, ideias, discursos, peças de design, objetos e estilos de vida. E como camadas de um mesmo visual a ser trajado, os indivíduos vão sobrepondo os produtos desse consumo identitário. No texto La Pensée Bourgeoise, que compõe o livro Cultura e Razão na Prática (2003, p. 181), de Marshall Sahlins, o indivíduo é apontado como alguém sofisticado em sua existência: "os homens não fazem apenas 'sobreviver': eles sobrevivem de maneira específica".

É justamente essa busca por estilos de vida por meio do qual os indivíduos escolhem "sobreviver" - as tais "maneiras específicas" apontadas por Shalins - que direciona os indivíduos consumidores aos discursos das marcas, as quais propõem identidades a serem vestidas por meio do consumo. Hoje, um indivíduo pode ter uma atitude mais prática e direta quanto à questão ambiental, por exemplo, e plantar uma árvore, fazer menos uso do plástico e/ou racionalizar o consumo doméstico de água. Ou simplesmente consumir produtos de marcas que o fazem e, de alguma forma, "vendem" essa atitude, terceirizando o atributo "ambiental", em seu branding, como valor. Afinal, como bem pontuou a artista plástica norte-americana Bárbara Krugman, ao reler com lentes contemporâneas Descartes: "eu consumo, logo existo!" (SLATER, 2002, p. 45 apud MARTINELLI; SANTA CRUZ, 2007, p. 3). Corroborando esse pensamento, Jair Ferreira dos Santos (2006, p. 13), ao 
discorrer sobre a alegria enquanto commodity, conclui que "o valor básico é a imagem de marca porque ela vende estilos de vida, formas de existir e se comportar em que o produto é apenas referência secundária".

Para Douglas e Isherwood (2004, p. 116), o ato de consumir é o ato de utilizar os bens de modo a tornar tangível um estilo de vida, uma percepção do indivíduo diante da sociedade, a qual classifica o tempo todo pessoas e eventos: "o indivíduo usa o consumo para dizer algumas coisas sobre si mesmo, sua família, sua localidade, seja na cidade, seja no campo, nas férias ou em casa. A espécie de afirmações que ele faz depende da espécie de universo que habita". É por meio do consumo de moda de marcas ditas sustentáveis que o indivíduo pode construir, a partir do olhar do grupo ao qual pertence, uma percepção identitária e de estilo de vida que dialoga com a questão socioambiental. É aqui que uma camiseta ou um par de jeans se torna mensagem, texto de um statement pessoal. "Para obter e conservar a consideração alheia não é bastante que o homem tenha simplesmente riqueza ou poder. É preciso que ele patenteie tal riqueza ou poder aos olhos de todos, porque sem prova patente não lhe dão os outros tal consideração" (VEBLEN, 1988, p. 22).

Vinte anos depois, Douglas revisitou sua própria tese e observou com perspicácia que o consumo, por consequência, produz o tipo de sociedade na qual o consumidor vive - sociedade essa que tem demonstrado maior preocupação com a sustentabilidade da sua existência. "Consumo é o processo de transformar mercadorias em bem-estar. Nem os bens, nem os objetos, mas a sociedade é o produto" (DOUGLAS, 1999).

\section{CONSIDERAÇÕES FINAIS}


É curioso observar o branding de uma marca pertencente a esta que é, aproximadamente, a sétima indústria mais poluente do mundo (ECOCULT, 2018) basear seu discurso e seu apelo de vendas em uma causa socioambientalmente responsável como a sustentabilidade. Mais curioso que isso é poder constatar, com pesquisa e análise, que, diferentemente de algumas narrativas de marketing, o caso da Osklen passa ao largo de ser mero discurso. O que pôde-se identificar é um trabalho sólido sendo feito há décadas que perpassa decisões e escolhas, iniciativas sociais e ambientais as quais resvalam no produto e, com isso, a marca se vê autorizada pelo seu próprio público - que valida suas ações - a incorporar a causa sustentável como espinha dorsal do seu branding.

Desse modo, o consumo, enquanto dispositivo social, permite que não apenas o discurso de marca seja incorporado pelos indivíduos que a consomem, mas também que os indivíduos assimilem, à sua maneira, uma narrativa de estilo de vida aos bens adquiridos. Se para Douglas e Isherwood (2004), o consumo em si próprio é mensagem enviada, para Appadurai (2008), ele é o ponto de convergência que, além de emitir, também recebe tais mensagens. Assim, pode-se atribuir uma característica sistêmica do consumo a essa relação marca <> produto <> consumidor. Nas palavras de Douglas e Isherwood (2004, p. 36): "os bens são neutros, seus usos sociais; podem ser usados como cercas ou como pontes".

\section{REFERÊNCIAS}

APPADURAI, Arjun. (Org.). A vida social das coisas: as mercadorias sob uma perspectiva cultural. Niterói: Editora da UFF, 2008.

BROWN, Lester. Eco-Economia. UMA - Universidade Livre da Mata Atlântica. Disponível em: 
<http://www.biodiversidade.rs.gov.br/arquivos/1161806787 Eco_Economia.pdf>. Acesso em: 20 de mai. 2018.

DISITZER, Marcia. ASAP (As Sustainable As Possible): Osklen desfila coleção no SPFW. 2018. Disponível em: <https://vogue.globo.com/moda/modanews/noticia/2018/04/asap-sustainable-possible-osklendesfila-colecao-no-spfw.html>. Acesso em: 27 abr. 2018.

DOUGLAS, Mary; ISHERWOOD, Baron. O mundo dos bens. Rio de Janeiro: Editora da UFRJ, 2004.

Disponível em:

O mundo dos bens, vinte anos depois. 2007.

<http://www.scielo.br/scielo.php?script=sci_arttext\&pid=S0 104-71832007000200002>. Acesso em: 3 jun. 2018.

DUARTE, Pedro. Entrevista. Revista Cause. Rio de Janeiro, n. 5, p. de 142-153, jul. 2017.

\section{ECOCULT. Fashion is the 8th most polluting industry?} 2017. Disponível em: <https://ecocult.com/now-knowfashion-5th-polluting-industry-equal-livestock/>. Acesso em: 12 jun. 2018.

INSTITUTO E. Sobre. Disponível em: < http://institutoe.org.br/sobre/>. Acesso em: 14 jun. 2018. KELLER, K. L. ; LEHMANN, D. R. Brands and branding: research findings and future priorities. Marketing Science, $v$. 25, n. 6, p. 740-759, 2006.

MARTINELLI, F.; SANTA CRUZ, L. Cultura como estratégia de mercado das marcas socialmente responsáveis. In: $3^{\circ}$ CONGRESSO DE ESTUDANTES DE PÓS-GRADUAÇÃO EM COMUNICAÇÃO, UERJ, Rio de Janeiro, 2008. . O engajamento social como estratégia de comunicação: consumo e responsabilidade no discurso empresarial. In: II ENCONTRO ESPM DE COMUNICAÇÃO E MARKeting, São Paulo. Anais... São Paulo, 2007, p. 3 MUNDIM, M. Ecologia: por um ambiente inteiro: Sustentabilidade e desenvolvimento sustentável. 2012. Disponível em:

<http://ecologambiente.blogspot.com.br/2012/02/ sustentabilidade-e-desenvolvimento.html>. Acesso em: 14/06/2018.

OSKLEN. [Anúncio Publicitário] Elle, 2018, p. 20.

OSKLEN. Campanha ASAP. 2018. Disponível em: <https://www.osklen.com.br/asap>. 
Acesso em: 18 abr. 2018.

ROBERTS, Kevin. Lovemarks - o futuro além das marcas. São Paulo: Makron Books, 2004.

SAHLINS, Marshall. Cultura e razão prática. Rio de Janeiro: Jorge Zahar Editor, 2003.

SANTOS, Jair Ferreira dos. Notas sobre a alegria como commodity. ECO-PÓS, v. 9, n. 2, p.13-19, agostodezembro 2006.

SLATER, Don. Cultura do consumo e modernidade. São Paulo: Nobel, 2002.

VEBLEN, Thorstein. A teoria da classe ociosa: um estudo econốmico das instituições. 3. ed. São Paulo: Nova Cultural, 1988. 